\title{
Ciências Sociais na formação de profissionais da saúde
}

\author{
Social Sciences in the health professionals' formation
}

Ciencias Sociales en la formación de profesionales de la salud

SAÚDE, SOCIEDADE E CULTURA: CIÊNCIAS SOCIAIS E HUMANAS PARA GRADUAÇÃO EM SAÚDE. Nascimento MC, Guedes CR. São Paulo: Editora Hucitec; 2017. 226 p. ISBN 978-85-84040-97-1.

doi: 10.1590/0102-311X00005319

O livro Saúde, Sociedade e Cultura: Ciências Sociais e Humanas para Graduação em Saúde é uma coletânea de 16 capítulos, organizada por duas professoras do Departamento de Saúde e Sociedade do Instituto de Saúde Coletiva, da Universidade Federal Fluminense.

A obra parece compor de forma providencial um panorama temático do campo das Ciências Sociais ao se dedicar à graduação, nível pouco privilegiado por trabalhos que têm visado mais às disciplinas da pós-graduação 1 . Nesse sentido, pensados e escritos com o olhar direcionado aos estudantes de cursos da área da saúde, os capítulos primam por uma linguagem mais próxima a seu público-alvo, com textos relativamente curtos, trazendo temas cruciais que motivam os estudantes. A pretensão dos autores é que o livro se torne uma referência nos conteúdos de Ciências Sociais e Humanas para os profissionais de saúde em formação.

Os capítulos foram divididos em três partes. A primeira parte é dedicada à Cultura e Subjetividade no Cuidado, composta por cinco textos. $\mathrm{O}$ primeiro capítulo discute as dimensões subjetivas da clínica e como é complexo lidar com a singularidade do sofrimento. Traz conceitos fundamentais como o de clínica ampliada e o de tecnologias leves, e como contribuem para incorporar dimensões subjetivas e sociais no cuidado em saúde, com exemplos concretos. O segundo apresenta a Antropologia como uma ferramenta para os profissionais de saúde, em um texto com leitura agradável e de fácil compreensão, que discutiu conceitos fundamentais como cultura, alteridade, evolucionismo e relativismo cultural, as formas de compreensão da doença, da experiência da doença e os modelos explicativos que envolvem esta experiência, os sistemas de cuidado e os itinerários terapêuticos. Esses capítulos iniciais, que apresentam conceitos ancorados em autores clássicos das Ciências Sociais, parecem preparar o leitor para apreender a crítica, ora implícita, ora explícita no decorrer do livro, sobre a desumanização das práticas e a tecnificação das relações entre profissionais e usuários dos cuidados em saúde.

O terceiro capítulo discute as tensões a que os médicos estão submetidos no desempenho de sua profissão, seus sentimentos de sobrecarga e frustração por não terem formação suficiente para compreender seu papel social e as características da sociedade onde trabalham. No calor dessa reflexão, a autora do capítulo afirma que os ideais médicos estão sobrecarregados por dois mitos: o de uma ciência positivista e o de um humanismo perdido. Assim, o sentimento de com- 
paixão e o desejo de cuidar do outro estão subsumindo na medicina dos dias atuais.

O quarto capítulo discute as influências da cultura sobre o processo saúde/doença, trazendo perspectivas da saúde bucal, mas perfeitamente aplicadas à saúde geral. O quinto discute como o estresse afeta a saúde. Talvez esse capítulo seja o que mais destoou dos demais, pois mesmo trazendo um tema atual e usado no campo das ciências sociais e de saúde, privilegiou questões biológicas e bioquímicas.

Na parte II, quatro capítulos compõem o tema Diferentes Concepções e Estratégias de Cuidado. Ao abrir esse conjunto de textos, as organizadoras introduzem uma reflexão sobre o modelo biomédico tradicional, marcado por seu caráter intervencionista, biologicista, mecanicista e com foco central na doença que tem sido colocado em xeque. Isso ocorre porque esse modelo abre pouco ou nenhum espaço para a dimensão simbólica da racionalidade médica, mesmo que ela esteja presente o tempo todo na prática profissional. As críticas ao sistema biomédico poderiam ser baseadas em diversos aspectos, mas são direcionadas para a supervalorização da neutralidade e objetividade que leva ao distanciamento entre profissionais e pacientes que estabelecem uma relação cada vez mais deteriorada. Nesse sentido, observa-se que "o papel milenar terapêutico da medicina, como arte de curar, em proveito da diagnose e da ciência das doenças" (p. 83) parece estar esmaecido. Com base nessa crítica, novos rumos para a biomedicina contemporânea são apontados no final do sexto capítulo.

Os capítulos sétimo ao nono trazem discussões caras ao campo das Ciências Sociais aplicadas à saúde 2 , como as racionalidades médicas vitalistas e práticas integrativas e complementares, experiências de arteterapia como um exercício estratégico na busca por integralidade na formação médica e medicalização da vida.

A parte III do livro é composta por sete textos, com o tema Educação Popular, Internet e Controle Social em Saúde. No décimo capítulo, encontram-se reflexões sobre as dimensões educativas das práticas em saúde, assumindo que na relação de cuidado o processo educativo ocorre até mesmo de forma não intencional ou não formal. Assim, consideram que formar profissionais comprometidos com a educação em saúde é fundamental para promover autonomia e saúde. No décimo primeiro capítulo, a relação médico/ paciente é abordada baseando-se nos impactos do "dilúvio de informações sobre saúde" disponíveis na Internet. Para os autores, esse amplo acesso a informações de variadas fontes funciona como controle dos pacientes que podem conferir ou complementar o diagnóstico ou explicações sobre suas condições de saúde oferecidos pelos médicos.

O décimo segundo texto reflete sobre o controle social e a formação em saúde valendo-se das contribuições da reforma sanitária italiana para a brasileira e das bases legais que constituíram o Sistema Único de Saúde (SUS). As instâncias de controle social na área da saúde são evocadas como lugar privilegiado de participação popular nas decisões sobre gastos públicos com o direito à saúde, corresponsabilizando profissionais de saúde no fortalecimento do SUS e seus princípios.

A atenção integral às pessoas com deficiência é o tema do décimo terceiro capítulo, que focaliza os direitos e as políticas que orientam a organização dos serviços para atender às especificidades deste grupo social. O envelhecimento é o tema do capítulo seguinte que aborda questões muito caras à gerontologia como a promoção da saúde e prevenção das doenças mais comuns na velhice, a visão que se tem do corpo, afeto e sexualidade nesta fase da vida, vivências de violência e instituições de longa permanência para idosos como uma das dimensões do cuidado.

Os dois últimos capítulos do livro tratam de um tema que costuma ser bastante sensível aos futuros profissionais de saúde em formação: a terminalidade da vida. O décimo quinto capítulo é dedicado ao cuidado possível além das promessas de cura e como se preparar para cuidar de alguém que tem um prognóstico ruim, um paciente terminal. No derradeiro capítulo, o enfoque é dado à "boa morte" e ao direito a viven- 
ciar a última fase do ciclo de vida com cuidado adequado e ético.

O conteúdo do livro suscita reflexões sobre como os temas e conceitos mais caros às Ciências Sociais estão sendo abordados na formação dos profissionais de saúde e como podem contribuir para uma formação humanística, mais conectada à individualidade, sem perder de vista o coletivo, em que os processos de saúde, doença, cuidado, cura e morte são construídos. Esse é o seu ponto forte. A novidade é que no decorrer dos capítulos os autores apresentam as experiências de ensino e como abordam os temas na graduação. Os desafios para docentes das disciplinas de Ciências Sociais aplicadas à saúde são daí depreendidos.

A experiência das autoras da resenha, como docentes dessa área no curso de medicina, tem mostrado que é fundamental não perder de vista as referências que forjaram o campo das ciências sociais na área da saúde, mas é urgente ampliar os olhares para a inclusão de questões sociais cada vez mais complexas e que exigem novas metodologias de estudo, novas formas de aproximação dos estudantes e de abordagem da diversidade de objetos afeitos a esta disciplina. Isso faz com que a obra seja indicada a docentes e profissionais em formação.

Assim como afirma Canesqui 3 (p. 20): "saúde e doença não são objetos tão modernos, mas se transformam e influenciam-se pelos novos objetos, simultaneamente pertencentes à natureza e à cultura". Temas como sexualidade e gênero, comunicação em saúde 2 , migração, vulnerabilidade social, violências, interseccionalidades e adoecimento dos próprios profissionais de saúde não foram abordados no livro, mas emergem da vida social e da experiência docente como fundamentais para a formação dos futuros profissionais que serão responsáveis pelo fortalecimento e continuidade do SUS.

\author{
Adalgisa Peixoto Ribeiro 1 \\ Graziella Lage Oliveira 1 \\ ${ }^{1}$ Faculdade de Medicina, Universidade Federal de Minas \\ Gerais, Belo Horizonte, Brasil. \\ adalpeixoto@yahoo.com.br
}

\section{Colaboradores}

As autoras participaram igualmente da concepção à escrita e revisão final do texto.

\section{Informações adicionais}

ORCID: Adalgisa Peixoto Ribeiro (0000-00019415-8068); Graziella Lage Oliveira (0000-00023387-3583).

1. Nunes ED. História e paradigmas da saúde coletiva: registro de uma experiência de ensino. Ciênc Saúde Colet 2011; 16:2239-43.

2. Canesqui AM. Ciências sociais e saúde no Brasil. São Paulo: Editora Hucitec; 2007.

3. Canesqui AM. Sobre a presença das ciências sociais e humanas na saúde pública. Saúde Soc 2011; 20:16-21.
Recebido em 10/Jan/2019

Versão final reapresentada em 12/Fev/2019

Aprovado em 25/Fev/2019 